\title{
Growth and Phytoremediation Potential of Watercress Nasturtium officinale R. Br. in Ammonium-rich Wastewater
}

\section{Saied Ali Musavi, Naser Karimi*, Soroor Sadeghi}

'Department of Chemical Engineering and Biotechnology, Faculty of Basic Science, Kermanshah Branch, Islamic Azad University, Kermanshah, Iran

Study Area: Kermanshah City, Kermanshah Province, Iran

Coordinates: $34^{\circ} 18^{\prime} 51^{\prime \prime} \mathrm{N} ; 47^{\circ} \mathrm{O} 3^{\prime} 54^{\prime \prime} \mathrm{E}$

Key words: Wastewater treatment, Ammonium Pollutant removal

\section{Abstract}

Phytoremediation is considered to be eco-friendly and eff icient technology for the removal of pollutants present in wastewater. Nowadays the focus is to look for a sustainable approach in developing wastewater treatment capability in rapidly increasing. The main objective of this paper is to review the possibility of using watercress (Nasturtium officinale) for the removal of ammonium ion present in high-strength industrial wastewater. It was found that there was no significant reduction of shoot height, root length and total biomass of watercress due to an increase in $\mathrm{NH}_{4}+$ concentrations. Statistical analysis indicates that the length of roots were significantly $(\mathrm{P}<0.05)$ increased at $\mathrm{NH}_{4}+$ rich waste water supply levels of $20-25 \%$ while compared to the control. The plants accumulated large amounts of ammonium ion or nitrogen in tissues under conditions of abundant supply. The removal efficiency of raw waste water was around $66 \%$ for nitrogen, $23 \%$ for calcium, $25 \%$ for total hardness, $22 \%$ for biological oxygen demand and $38 \%$ of chemical oxygen demand. Nutrient removal efficiency was positively correlated with the initial nutrient supply. The results show that N.officinale grown in the fixed mat economic plant-based treatment system may be an effective, low-cost phytoremediation technology to treat water containing a higher concentration of ammonium.

processes like absorption, degradation, or stabilization.

Two main processes for nitrogen removal are: a) Oxidation of ammonium to nitrite, followed by oxidation of nitrite to nitrate in oxygen rich environment (nitrif ication process) b) Reduction of nitrate to nitrite, followed by the reduction of nitrite to nitrogen gas (denitrification under oxygen deficient conditions). In different municipal and industrial processes many nitrogen-rich streams are produced with a low content of biodegradable organic matter (Siegrist et al., 1998; Zimmo et al., 2004). In wastewater treatment plants with anaerobic sludge digestion, $15 \%$ of the inlet nitrogen load is recycled with the return of liquors from sludge dewatering. Separate treatment of this digester supernatant, containing 600 g.m- $3 \mathrm{NH}_{4} \mathrm{~N}$ would signif icantly reduce the nitrogen load of the mainstream and improve nitrogen elimination (Fux et al., 2003). Chemical elimination, or with air stripping is feasible but is much more expensive (Siegrist, 1996).

In the recent past years de-ammonification processes, various organic and inorganic pollutants through

*Corresponding Author: nkarimi@razi.ac.ir 
as a new technology for the treatment of nitrogen rich wastewaters, have been developed (Helmer et al., 2000; VanDongen et al., 2001). The introduction of deammonification process can reduce the cost of plant operation and make the management more sustainable. Due to low growth rates of microorganisms denitrification process favors systems with long sludge retention times (biofilm systems), a system which continuously receives waste water, rich in ammonium and nitrite (VanDongen et al., 2001). Watercress, (N.officinale), is an edible aquatic plant. It commonly occurs in urban streams where it has been observed to achieve biomasses of up to $200 \mathrm{~g} \mathrm{~m}^{-2}$ and can dominate the aquatic plant assemblage (Ozturk et al., 2010). Watercress as a medicinal plant has been traditionally considered a diuretic, purgative and tonic, and consumed as a salad green (Ozturk et al., 2010). The properties of N.officinale that entail mental accumulation was extensively studied in the past. However, no studies to date have examined Nasturtium's growth, nutrient uptake responses and phytoremediation abilities to the large gradient of ammonium concentration typical of industrial wastewaters. Therefore, in this study, we investigated the in situ phytoremediation assays using the association of watercress plant during different proposed treatments in order to improve treated wastewater quality. The results of this study will provide a better understanding of the phytoremediation process.

\section{Materials and methods:}

Plant collection cultivation and wastewater treatments: Nasturtium officinale samples (in seedling stage) were collected in May of 2015 from the Ghaisavand Stream in Kermanshah, Iran. Prior to the experiment, plant culture media (containers) were disinfected with $1 \%$ (v.v) $\mathrm{NaClO}$ for 3-5 min thereafter rinsed three times with distilled water (Hou et al., 2007). Collected samples were washed in tap water and acclimatized for 5 days in a climate chamber with a water temperature of $18^{\circ} \mathrm{C}$, a relative humidity of $70 \%$ and light-dark photoperiod ofi $6 \mathrm{~h}$ light. 8 h dark. Containers were mildly aerated.

The experiments which arranged in this study were set-up in triplicate, wherein each replicate constituted approximately $6 \mathrm{~g}$ of the evaluated plants. The ammonium-rich wastewater solutions utilized in the present study were gained from Kermanshah ammonium ref inery, Iran. Each watercress sample was exposed to five varied test concentrations $(5,10,15,20$, and 25 percent) of ammonium-rich wastewater in separate $1000 \mathrm{~mL}$ conical flasks (Ozturk et al., 2010). The plants that were not exposed to wastewater served as the control groups of this experiment. The flasks that comprise the plant and wastewater concentrates were placed in a climate chamber under the aforementioned conditions for 30 days. Flasks were not aerated during the experiment. The change that occurred in the volume of the solution within the flasks due to evapotranspiration was compensated for by the addition of double distilled water. During the experiment period, leaves were harvested (usually eight per treatment) on day o (before treatment, time t1), day 15 (time t2) and day 30 (time $t_{3}$ ). The resultant plant samples in each harvesting time were collected and sieved with a plastic griddle. Each plant was rinsed with deionized water, drained, and then blotted on paper towels for $2 \mathrm{~min}$. Determination of growth parameters During each harvesting time, shoot height was measured from the culm base to the tip of the longest leaf and root length was measured from the root-shoot junction to the tip of the longest root. Before treatment and on harvesting, the root and shoot biomass pot-1 were measured.

Analytical procedures: The Nessler method was used for analyses ammonium ion in wastewater, In the ammonia test, Nessler Reagent $\left(\mathrm{K}_{2} \mathrm{HgI}_{4}\right)$ reacts with the ammonium ion present in the sample (under strongly alkaline conditions) to produce a yellow-colored species. The intensity of the color is in direct proportion to the ammonium ion concentration.

The total concentration of calcium ion in each wastewater treatment was determined using Shimadzu AA-6200 atomic absorption spectrometer (HG-AAS; Shimadzu, Tokyo, Japan). The reference standard for calibration of the AAS was made using $1000 \mathrm{mg} \mathrm{L}^{-1}$ (Beach leaves material FD8, Commission of the European Communities, Joint Research Centre ISPRA). The samples were analyzed in triplicate. All analytical reagent grade used in this study were of Merck, Darmstadt, Germany.

The chemical oxygen demand (COD) measurement was based on digestion with potassium dichromate in concentrated Sulphuric acid for $2 \mathrm{~h}$ at $150^{\circ} \mathrm{C}$. Biological oxygen demand (BOD) was determined titrimetrically, suspended solids were measured by using WHATMAN filter paper.

Physical parameters like $\mathrm{pH}$ and TDS were determined by a portable combine meter (Milwaukee, model $\mathrm{SM}_{2} \mathrm{o}_{2}$ ) and $\mathrm{TH}$ was measured by the following equation: $\mathrm{TH}=$ 2.497 Ca + 4.115 Mg (Vasanthavigar et al., 2010).

Statistical analysis Values of all data are expressed as mean \pm SD. The one-tailed paired Student's t-test was used to determine statistical significance between the untreated and treated parameters at $\mathrm{P}<0.05$. All analyses were carried out in triplicate.

\section{Results and Discussion :}

Effects of ammonium rich wastewater on growth of watercress: the suppression of growth and yield in $\mathrm{NH}_{4}+$ -sensitive species can be severe, and for this reason, $\mathrm{NH}_{4}+$ toxicity is of major importance in agricultural and ecological settings. Certain plant species and even families are particularly sensitive to or tolerant of $\mathrm{NH}_{4}{ }^{+}$as the sole 
nitrogen source. In general, the biomass of plants may be an important index in identifying them as a tolerant and an accumulator. Therefore, this parameter should not decrease significantly at the threshold concentration of plant growth inhibition. The total biomass was measured at the end of the experiment and is presented in figure 1. During the 30-day exposure to different content of ammonium rich wastewater $(0-25 \%)$, the biomass of watercress did not show any visual symptoms.

There was no significant reduction $(\mathrm{P}<0.001)$ of shoot height observed due to an increase in $\mathrm{NH}_{4}^{+}$concentrations. It is revealed that the length of roots was significantly $(\mathrm{P}<0.05)$ increased at $\mathrm{NH}_{4}{ }^{+}$wastewater supply levels of $20-$ $25 \%$ compared to the control. The maximum root length at $25 \% \mathrm{NH}_{4}^{+}$was about 1.23 fold of the control (Fig.- 2).

Based on these growth traits, it is suggested that watercress was considerably tolerant to $\mathrm{NH}_{4}^{+}$riches wastewater. Because tolerance to metal toxicity is a crucial characteristic for hyperaccumulators or accumulators, therefore watercress had the potential for use in phytoremediation of $\mathrm{NH}_{4}^{+}$-polluted wastewaters. The results of the physicochemical parameters of wastewater study are presented in Table 1 , after multiplying the values by the dilution factor. The hydrogen-ion concentration $(\mathrm{pH})$ is an important quality parameter of wastewater. Table 1 shows that the $\mathrm{pH}$ of the influent (raw wastewater) was measured to be 8.5 compared to 8.8 with treated effluent. On $5 \%$, $\mathrm{pH}$ of the effluent increased from 8.5 to 8.8 and maintained thereafter, furthermore total dissolved solids (TDS) was enhanced from o to $25 \%$ wastewater treatment. In each $\mathrm{NH}_{4}^{+}$wastewater treatment, TDS was increased from 0 - 30 days of treatment periods (Table-1). The values show TDS are in the permissible limit as compared with Indian standards. The watercress treatment resulted in a significant reduction in total hardness in each treatment by about $25 \%$. Free ammonia levels were reduced by $66 \%$ at 30 th days in $25 \%$ wastewater treatment (Fig.- 3). Calcium also followed a similar trend with $23 \%$ reductions (Figure 4 ). Reductions in biochemical oxygen demand (BOD) and chemical oxygen demand (COD) levels were $22 \%$ and $38 \%$, respectively, during the Phytoremediation process (Table 1). The BOD and COD levels of influent wastewater varied from 4.73-4.8 mg.l and 9.4-22.9 mg.l respectively. Whereas the BOD and COD levels of effluent varied from 3.33-2.86 mg.l and 11.033-20.33 mg.l respectively. Fig. ${ }^{-5} \& 6$ shows the levels of $\mathrm{BOD}$ to a certain extent due to the biological treatment process for which the effluent is treated which consists of equalization, primary clariflocculator, aeration tank and the secondary clariflocculator. Biological treatment process results in oxidation of organic matter, which provides energy for the microbial metabolic process.

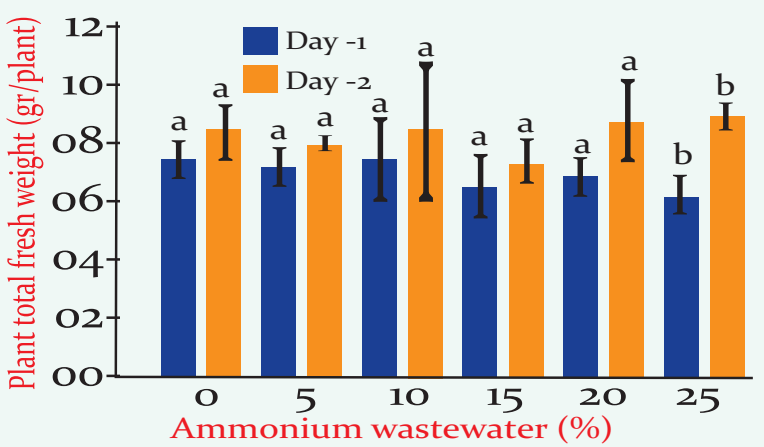

Figure-1: Effect of ammonium-rich wastewater on plant fresh mass of watercress ( $N$. officinale). The bars having similar letters do not signif icantly different at $\mathrm{P}<0.05$ (T-test). $\mathrm{N}=5$.

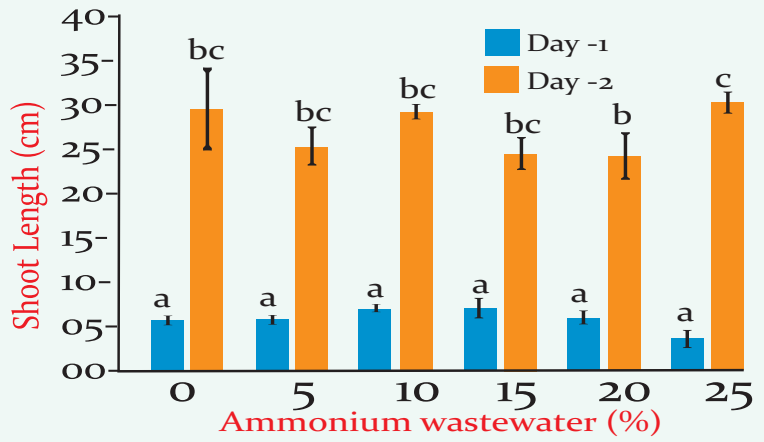

Figure-2: Effect of ammonium-rich wastewater on shoot length $(\mathrm{cm})$ of watercress ( $N$. officinale ). The bars having similar letters do not signif icantly different at $\mathrm{P}<0.05$ (T-test). $\mathrm{N}=5$

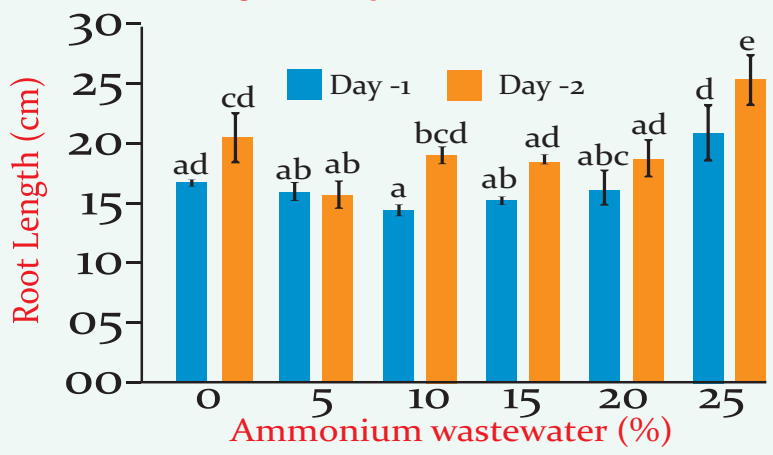

Figure-2: Effect of ammonium-rich wastewater on root length $(\mathrm{cm})$ of watercress ( $N$. officinale). The bars having similar letters do not significantly different at $\mathrm{P}<0.05$ (T-test). $\mathrm{N}=5$

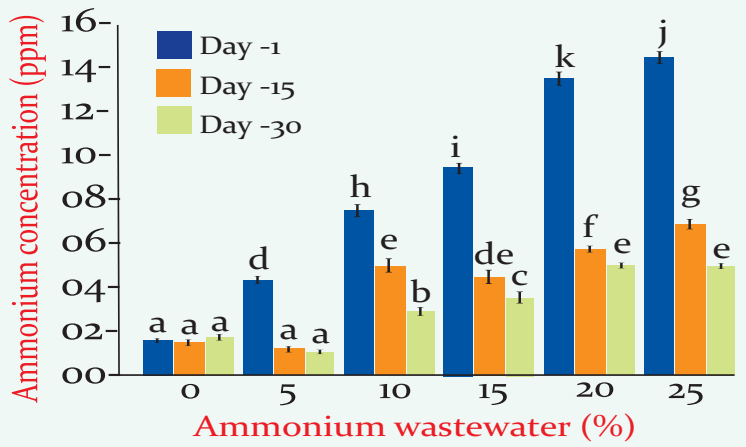

Figure-4: Effect of ammonium-rich wastewater on shoot ammonium concentration of watercress ( $N$. officinale). The bars having similar letters do not significantly different at $\mathrm{P}<$ 0.05 (T-test). $\mathrm{N}=5$. 


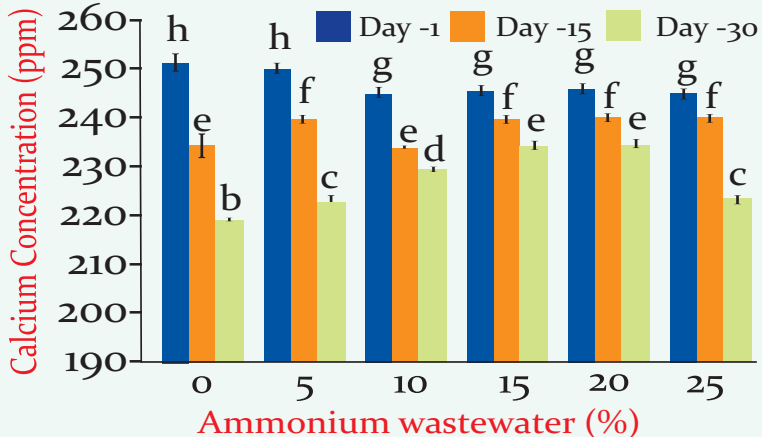

Figure-5: Effect of ammonium-rich wastewater on shoot calcium concentration of watercress (N.officinale). The bars having similar letters do not signif icantly different at $\mathrm{P}<0.05 \cdot \mathrm{N}=5$.

Table 1.: Physico-chemical parameters of ammonium-rich wastewater after purification by watercress ( $N$. officinale).

\begin{tabular}{|c|c|c|c|c|c|}
\hline $\mathrm{EP}(\text { day })^{*}$ & $\mathrm{pH}$ & TDS & $\mathrm{TH}$ & BOD & COD \\
\hline \multicolumn{6}{|c|}{ Treatment (wastewater percentage) Control } \\
\hline o & 8.5 & 15.00 & 576.66 & 4.80 & 9.40 \\
\hline 15 & 8.5 & 18.00 & $379 \cdot 33$ & 3.93 & 9.00 \\
\hline 30 & 8.5 & 21.00 & 365.66 & $3 \cdot 33$ & 11.03 \\
\hline \multicolumn{6}{|c|}{ Treatment (wastewater percentage) 5} \\
\hline o & 8.8 & $15 \cdot 50$ & 580 & $4 \cdot 50$ & 11.00 \\
\hline 15 & 8.8 & $17 \cdot 50$ & 393.66 & 4.26 & 8.99 \\
\hline 30 & 8.8 & $19 \cdot 50$ & 374.00 & 3.80 & 12.99 \\
\hline \multicolumn{6}{|c|}{ Treatment (wastewater percentage) 10} \\
\hline o & 8.8 & 16.166 & 583.33 & 4.03 & 19.99 \\
\hline 15 & 8.8 & 19.166 & 419.00 & 3.46 & 17.00 \\
\hline 30 & 8.8 & 21.166 & 389.00 & 2.90 & 18.00 \\
\hline \multicolumn{6}{|c|}{ Treatment (wastewater percentage) 15} \\
\hline o & 8.8 & 16.33 & 580.66 & 4.76 & $17 \cdot 99$ \\
\hline 15 & 8.8 & 18.50 & 435 & 4.033 & 14.00 \\
\hline 30 & 8.8 & 22.16 & 400 & $3 \cdot 53$ & 18.99 \\
\hline \multicolumn{6}{|c|}{ Treatment (wastewater percentage) 20} \\
\hline o & 8.8 & 16.16 & 575 & 4.60 & 22.99 \\
\hline 15 & 8.8 & 19.16 & $444 \cdot 33$ & 3.80 & 21.00 \\
\hline 30 & 8.8 & 21.50 & 404.00 & 2.90 & 20.33 \\
\hline
\end{tabular}

${ }^{*}$ Exposure period (day)

\section{Conclusion:}

Our study concluded that Nasturtium officinale is a very efficient in remediating Nitrogen (ammonium) contaminants. The treatment also improved the Physicochemical characteristics of the wastewater such as colour, $\mathrm{pH}$, TDS, BOD and COD values. The treated effluent from the system has met the wastewater effluent Standards, making it acceptable for recycling in flushing the urinals and water closets, then for gardening and other related purposes. Thus N.officinale could be recommended for Nitrogen bioremediation in domestic and industrial wastewater.

Acknowledgements:

We wish to thank the head of plant physiology lab of Razi University, for her assistance in chemical analysis.

\section{References:}

Fux, C., Lange, K., Faessler, A., Huber, P., Grueniger, B. \& Siegrist, H. (2003): Nitrogen removal from digester supernatant via nitrite SBR orSHARON? Water Sci. Technol. 48(8): 9-18.

Helmer, C., Tromm, C., Hippen, A., Rosenwinkel, K.H., Seyfried, C.F. \& Kunst S. (2000): Single stage biological nitrogen removal by nitritation and anaerobic ammonium oxidation in biofilms systems, IWA Conference Proceedings, Paris, France, 3-7 July 2000.

Hou, W., Chen, X., Song, G., Wang, Q. \& Chang, C.C. (2007): Effects of copper and cadmium on heavy metal polluted water body restoration by duckweed (Lemna minor) Physiology. Plant Biochem., 45: 62-69.

Noemi, R., Moshe, A. \& Gideon, O. (2004): A pilot study of constructed wetlands using duckweed (Lemnagibba L.) for treatment of domestic primary effluent in Israel. Water Res. 38:2241-2248.

Siegrist, H. (1996): Nitrogen removal from digester supernatant:.comparison of chemical and biological methods. Wat. Sci. Tech., 34 (1-2):399-406.

Siegrist, H., Reithaar, S., Koch, G. \& Lais, P. (1998): Nitrogen loss in a nitrifying rotating contactor treating ammonium-rich wastewater without organic carbon. Wat.Sci.Tech., 38(8-9): 241-248.

Tak, H.I, Ahmad F, Babalola O.O. \& Inam A. (2012): Growth, photosynthesis and yield of chickpea as influenced by urban wastewater and different levels of phosphorus. Int. J. Plant Res. 2: 6-13.

Tak, H.I, Inam ,A. \& Inam, A. (2010): Effects of urban wastewater on the growth, photosynthesis and yield of chickpea under different levels of nitrogen. Urban Water J. (7):187-195.

Ozturk, F., Duman, F., Zeliha, L. \& Temizgul, R. (2010): Arsenic accumulation and biological responses of watercress (Nasturtiumofficinale R. Br.) exposed to arsenite. Environ. Experiment.Bot. 69(2):167-174.

Ruiz-Marin, A., Mendoza-Espinosa, L.G. \& Stephenson, T. (2010): Growth and nutrient removal in free and immobilized green algae in batch and semi-continuous cultures treating real wastewater. Bioresour. Technol., 101:58-64.

vanDongen, L.G.J.M., Jetten M.S.M. \& vanLoosdrecht, M.C.M. (2001): The combined Sharon/Anammox Process, A sustainable method for $\mathrm{N}$-removal from sludge water. STOWA Report, IWA Publishing, London, UK

Vacca, G., Wandb, H., Nikolausza, M., Kuschka, P., Kastner, M. (2005): Effect of plants and filter materials on bacteria removal in pilot-scale constructed wetlands. Water Res., 39: 1361-1373.

Vasanthavigar, M., Srinivasamoorthy, K., Vijayaragavan, K., Ganthi, R.R., Chidambaram, S., Anandhan, P., Manivannan, R., Vasudevan, S. (2010): Application of water quality index for groundwater quality assessment: Thirumanimuttar subbasin, Tamilnadu, India. Environ. Monitor. Assess., 171 (1-4): 595-609

Zimmo, O.R., van der Steen, N.P, Gijzen, H.J (2004): Nitrogen mass balance across pilot-scale algae and duckweed-based wastewater stabilisation ponds. Water Res.,38:913-920. 